\title{
Telemonitoring should have a central role in future health care
}

This article was published in the following Dove Press journal:

International Journal of General Medicine

10 May 2013

Number of times this article has been viewed

\section{Ashley Yarrow-Jenkins Thomas I Lemon \\ School of Medicine, Cardiff University, University Hospital of Wales, Cardiff, Wales}

Correspondence: Thomas I Lemon School of Medicine, Cardiff University, University Hospital of Wales, Heath Park, Cardiff CFI 4 4XW, Wales

Email lemonti@cf.ac.uk

\section{Dear editor}

Firstly we would like to thank Upatising et al for undertaking an interesting and relevant study. ${ }^{1}$ Health professionals are well aware of the impending crisis that the aging demographics will have on future worldwide health care provision. With increasing hospital stays, "bed blocking," and longer duration of chronic illness as a result of increasing life expectancy the crisis is indeed underway.

With shifting society, the attitudes and expectations of health care are changing significantly. With increased pressures on waiting list times, drug provision/administration, and service provision, patients become more critical and budgets become tighter. Outside of health care the technological advancement is astonishing. Smartphones, robotics, tablets, the internet has truly revolutionized health care provision and training in countless ways.

The proposed union of this technological advancement with 'older adults,' as a mechanism to prevent hospitalisation through access to health care via telemonitoring is one which can help reduce the pressure on the health service. However more development and research needs to be undertaken to expand this proposal. Through the clinical use of telemedicine, frail individuals would be kept out of the hospital system, in which they often can become 'trapped;' allowing them to stay at home, where many wish to be. This equates to additional bed space, more nurse availability (as often these patients need more care than others), and a lesser reduction in mobility (very often frail patients in hospital become quickly immobile, which is unlikely to have occurred if they had still been at home).

An issue however surrounds the ever changing systems in health care, such as ObamaCare and the National Health Service in Great Britain. In these organizations with significant financial and political input from their governments, amendments and additions such as implementing telemedicine centrally, would be problematic and likely to have as many opponents as proponents given the results of this study.

This trial ${ }^{1}$ result failed to excite, however it does not stop one from turning to investigate more methods of how telemedicine could be used to provide better, more cost effective and patient-centered health care in the future. We strongly believe that telemedicine of this kind would be of benefit in the future. 


\section{Disclosure}

The authors report no conflicts of interest in this communication.

\section{Reference}

1. Upatising B, Hanson GJ, Kim YL, et al. Effects of home telemonitoring on transitions between frailty states and death for older adults: a randomized controlled trial. Int J Gen Med. 2013;6:145-151. 


\section{Author's response}

\author{
Benjavan Upatising' \\ Paul Takahashi \\ 'School of Industrial Engineering, Purdue University, West \\ Lafayette, IN, USA; ${ }^{2}$ Department of Internal Medicine, Mayo \\ Clinic, Rochester, MN, USA
}

Correspondence: Paul Y Takahashi

Department of Internal Medicine,

Mayo Clinic, 200 First Street SW,

Rochester, Minnesota 55905, USA

Tel +I 5072845944

Fax +I 5072660036

Email takahashi.paul@mayo.edu

\section{Dear editor}

We would like to thank Yarrow-Jenkins and Lemon for their letter to the editor regarding our recently published paper titled, "Effects of home telemonitoring on transitions between frailty states and death for older adults: a randomized controlled trial." We agree with you about that telemedicine has a potential to play a vital role in the future of healthcare and that further research and investigation need to continue, especially for the frail elderly population. Telemonitoring can provide benefits as you had stated. Our paper only focused on frailty as one potential benefit of telemonitoring. Unfortunately, we did not see an effect on frailty with the telemonitoring intervention.

One must be mindful of the evidence of the efficacy of telemonitoring as healthcare moves forward. One metaanalysis for COPD did show improvement in quality of life with a reduction in emergency room visits over 12 months, odds ratio (OR) 0.27 (95\% CI 0.11 to 0.66$){ }^{2}$ In another meta-analysis of congestive heart failure, one finds a reduction in heart failure hospitalizations with a relative risk of $0.79,95 \%$ CI 0.67 to $0.94, P=0.008 .^{3}$ These positive metaanalysis manuscripts reflect the positive aspects of telemonitoring in single disease states. Unfortunately, individual randomized trials of telemonitoring do not always find such positive results. ${ }^{4}$

We believe there will be a role for telemonitoring and telemedicine in healthcare in the future. There are clear needs for telemonitoring and telemedicine consultations for patients living in rural and remote areas without access to medical care. For patients with chronic illnesses, better decision support will likely be the key for improved telemonitoring. We fully agree that future work needs to continue, and we anticipate this work will be done by investigators striving to improve the care of our patients.

\section{Disclosure}

The authors report no conflicts of interest in this communication.

\section{References}

1. Upatising B, Hanson GJ, Kim YL, et al. Effects of home telemonitoring on transitions between frailty states and death for older adults, a randomized controlled trial. Int J Gen Med. 2013;6:145-151.

2. McLean S, Nurmatov U, Liu JL, et al. Telehealthcare for chronic obstructive pulmonary disease. Cochrane Database Syst Rev. 2011;7:CD007718.

3. Inglis SC, Clark RA, McAlister FA, et al. Structured telephone support or telemonitoring programmes for patients with chronic heart failure. Cochrane Database Syst Rev. 2010;8:CD007228.

4. Chaudhry SI, Mattera JA, Curtis JP, et al. Telemonitoring in patients with heart failure. The N Engl J Med. 2010;363(24):2301-2309.

\section{Publish your work in this journal}

The International Journal of General Medicine is an international, peer-reviewed open-access journal that focuses on general and internal medicine, pathogenesis, epidemiology, diagnosis, monitoring and treatment protocols. The journal is characterized by the rapid reporting of reviews, original research and clinical studies across all disease areas.

\section{Dovepress}

A key focus is the elucidation of disease processes and management protocols resulting in improved outcomes for the patient. The manuscript management system is completely online and includes a very quick and fair peer-review system. Visit http://www.dovepress.com/ testimonials.php to read real quotes from published authors. 